\title{
THE STEINER SYMMETRIZATION OF LOG-CONCAVE FUNCTIONS AND ITS APPLICATIONS
}

\author{
YOUJIANG LIN AND GANGSONG LENG
}

Abstract. In this paper, we give a new definition of functional Steiner symmetrizations on logconcave functions. Using the functional Steiner symmetrization, we give a new proof of the classical Prékopa-Leindler inequality on log-concave functions.

Mathematics subject classification (2010): 46E30, 52A40. equality.

Keywords and phrases: Rearrangements of functions, Steiner symmetrizations, Prékopa-Leindler in-

\section{REFERENCES}

[1] S. Artstein, B. Klartag, V. D. Milman, On the Santalò point of a function and a functional Santalò inequality, Mathematika 54 (2004), 33-48.

[2] F. BARTHE, On a reverse form of the Brascamp-Lieb inequality, Invent. Math. 134 (1998), 335-361.

[3] H. J. BRASCAMP, E. H. Lieb, J. M. LutTinger, A General Rearrangement Inequality for Multiple Integrals, J. Funct. Anal. 17 (1974), 227-237.

[4] A. BurChARD, Steiner symmetrization is continuous in $W^{1, p}$, Geom. Funct. Anal. 7 (1997), $823-$ 860.

[5] A. BURCHARD, A short course on rearrangement inequalities, available at http://www.math.utoronto.ca/almut/rearrange.pdf, 2009.

[6] A. Cianchi, N. Fusco, Strict monotonicity of functionals under Steiner symmetrization, in: Calculus of Variations: Topics from the Mathematical Heritage of E. De Giorgi, Quad. Mat., vol. 14, Dept. Math., Seconda Univ. Napoli, Caserta, 2004, pp. 187-220.

[7] A. Cianchi, N. Fusco, Steiner symmetric extremals in Pòlya-Szegö type inequalities, Adv. Math. 203 (2006), 673-728.

[8] M. FORTIER, Convergence results for rearrangements: Old and new, M.S. Thesis, University of Toronto, December 2010.

[9] R. J. GARDNER, The Brunn-Minkowski inequality, Bull. Amer. Math. Soc. 39 (2002), 355-405.

[10] G. PISIER, The volume of Convex Bodies and Banach Space Geometry, Cambridge Tracts in Math. 94, Cambridge University Press, Cambridge, 1989.

[11] R. SchneIder, Convex Bodies: The Brunn-Minkowski Theory, Encyclopedia Math. Appl., vol. 44, Cambridge University Press, Cambridge, 1993. 